\title{
Consecuencias socioespaciales de la transformación urbana. Un ejemplo en el estudio de Fuenlabrada, municipio metropolitano madrileño
}

josé Murillo Castillejo*

\section{RESUMEN}

Hacemos en este artículo una breve caracterización del espacio urbano de Fuenlabrada, municipio de la zona sur del Área Metropolitana de Madrid. Analizamos el crecimiento demográfico y residencial, así como las consecuencias sociales y espaciales que de éste se derivan a la luz del estudio del planeamiento urbanístico vigente en el municipio.

\section{ABSTRACT}

The aim of this paper is to show a short profile about urban space in Fuenlabrada, satellite town located in the Southern Metropolitan Area of Madrid. We study the diferents questions about demographic development and the modifications in the urban landscape. This process and the effects have remarkable repercusions in the most recent urban planning of the city.

\section{INTRODUCCIÓN}

Pretendemos subrayar aquí la importancia del crecimiento demográfico y urbano de un municipio metropolitano madrileño, situado en la Zona

(*) Doctor en Geografía. 
Suroeste de la Comunidad de Madrid, y las consecuencias socioespaciales que se derivan de la planificación urbana concretada en el Plan General de 1986. Nos parece también interesante destacar la próxima revisión que del Plan se va a emprender a mediados de los años noventa, para la cual consideramos de interés esta reflexión.

Incidiendo más en lo señalado, destacamos la transformación urbana durante los años setenta y los problemas heredados del crecimiento anárquico de la ciudad en esta década. Problemas que se derivan también de la ubicación de Fuenlabrada en la "frontera» del Área Metropolitana institucional. Es preciso conocer cómo el espectacular crecimiento del espacio edificado en estos años, y cómo la masificación de vivienda consiguiente que se produjo ha determinado a su vez una realidad formal «difícil» de cambiar por parte del planeamiento. Es precisamente el análisis de éste el que abordamos en este estudio, como elemento clave para entender la transformación urbana experimentada por la localidad a finales de los años ochenta y comienzo de los noventa.

En este análisis hemos concretado los puntos siguientes. Primero, la ubicación del municipio de Fuenlabrada en el marco espacial del Suroeste metropolitano madrileño, encuadrándolo en la zona y en el contexto del crecimiento demográfico de estos núcleos. En segundo lugar, una caracterización del espacio urbano de acuerdo con la transformación experimentada en estos últimos años y con los problemas heredados. En tercer lugar, una delimitación del espacio edificado que nos servirá para abordar el planeamiento urbanístico de Fuenlabrada: marco de desarrollo, objetivos y coordenadas generales de actuación y principales resultados del estudio. Concluiremos nuestro estudio viendo las connotaciones socioespaciales a la luz del planeamiento, que se traducen en una dinámica de crecimiento urbano muy diferente al de años pasados.

\section{FUENLABRADA EN EL MARCO ESPACIAL DE LA ZONA SUROESTE-1 DE LA REGIÓN MADRILEÑA}

\subsection{Ubicación de la zona y crecimiento histórico}

La zona en la que se encuadra nuestro municipio de estudio, tal como su denominación señala, se encuentra al Suroeste de la región madrileña y se estructura territorialmente de Oeste a Este en relación a una serie de viarios de salida de Madrid: la autovía de Extremadura, la carretera Leganés-Fuenlabrada y la Nacional 401 o autovia de Toledo, completándose con la carretera transversal que une dos de los tres términos municipales, 
la comarcal Móstoles-Fuenlabrada-Pinto. Se incluyen bajo la denominación de Suroeste-1 las localidades de Móstoles, Fuenlabrada y Parla.

Hasta los años sesenta este espacio tiene un carácter rural y una actividad económica volcada en el sector primario, sobre todo en la agricultura de secano y en menor medida en la ganadería que complementa a la primera. Responde esta descripción a la situación señalada para estos pueblos por el Diccionario Geográfico y Estadístico de Pascual Madoz a mediados del siglo pasado. A comienzos de los años cincuenta y según datos de la Diputación Provincial de Madrid, la población de estos núcleos, encuadrados en el partido judicial de Getafe era la siguiente: Fuenlabrada constituia el primer núcleo de población con 2.266 habitantes, seguido de Móstoles con 2.082 y Parla con 1.424; en total, 5.772 habitantes de hecho (DIPUTACIÓN DE MADRID, 1956: 117-140).

Con respecto al crecimiento histórico de Fuenlabrada podemos ofrecer algunos datos de particular interés. La primera referencia de su población la encontramos en las Relaciones Histórico-Geográfico-Estadística de los Pueblos de España, que señala para el año 1575 unos 350 vecinos, aproximadamente unos 1.315 habitantes. En 1848, Madoz da la cifra de 487 vecinos, que equivalen a 2.027 almas. A comienzos de este siglo son 2.211 habitantes y en el año 1960 solamente se ha llegado a los 2.481 residentes. Este pequeño aumento de la población a lo largo de casi quinientos años y el espectacular incremento en los últimos treinta (155.168 habitantes en 1993), sólo puede entenderse y explicarse a partir del cambio de rol que todos estos municipios han tenido en el contexto de la transformación metropolitana de la región madrileña. Una economía basada en la explotación de sus recursos no permitia aumentar la población más allá del crecimiento de éstos, por lo que el cambio obedece a su inserción metropolitana.

\subsection{Transformación urbana y crecimiento demográfico en el periodo reciente}

La población en los municipios de la Zona Suroeste-1 era de 7.148 habitantes en 1960, elevándose hasta 35.376 en 1970. Al finalizar la década se ha quintuplicado el número de residentes, aumento que es el resultado de un complejo proceso de difusión que afecta a buena parte de la región madrileña. Éste ya había tenido lugar en el pasado, concretándose primeramente en el crecimiento de la ciudad de Madrid, y posteriormente en los núcleos situados a lo largo de los principales viarios de comunicación. Crecimiento en saltos sucesivos, que ha afectado en primer lugar a los municipios más próximos a la capital y posteriormente a los más alejados. 
El crecimiento en los años setenta es todavía más intenso, llegándose en 1981 a los 284.674 habitantes, lo que supone multiplicar por ocho la población de once años antes. Este incremento no afecta por igual a los tres municipios, ya que unos aumentan su población antes que otros, por lo que pueden delimitarse varios períodos, siendo muy útil el estudio en intervalos quinquenales (fig. 1). Entre 1970 y 1975 es Móstoles el municipio que más crece $(327,56 \%)$, seguido de Parla $(199,25 \%)$ y Fuenlabrada $(150,42 \%)$. En el lustro siguiente será Fuenlabrada quien más incrementará los efectivos $(325,64 \%)$, seguido a gran distancia por Móstoles y Parla ( $97,04 \%$ y $84,27 \%$ respectivamente).

\begin{tabular}{|c|c|c|c|c|c|c|}
\hline \multicolumn{7}{|c|}{ POBLACIÓN DE LA ZONA SUROESTE-1. PERIODO: 1960-1991 } \\
\hline MUNICIPIOS/AÑO & AÑO 1960 & AÑO 1970 & AÑO 1975 & AÑO 1981 & AÑO 1986 & AÑO 1990 \\
\hline Móstoles & 2.886 & 17.836 & 76.260 & 150.260 & 175.133 & 192.018 \\
\hline Fuenlabrada & 2.481 & 7.327 & 18.348 & 78.096 & 119.848 & 144.723 \\
\hline Parla & 1.781 & 10.213 & 30.562 & 56.318 & 63.963 & 69.907 \\
\hline Zona Suroeste-1 & 7.148 & 35.376 & 125.170 & 284.674 & 358.944 & 406.648 \\
\hline \multicolumn{7}{|c|}{ Fuente: Censos y padrones. } \\
\hline \multicolumn{7}{|c|}{ INCREMENTO ABSOLUTO DE LA POBLACIÓN POR PERIOODOS: 1971-1990 } \\
\hline MUNICIPIOS/PERIODO & $1971-1975$ & 1976-1980 & $1981-1985$ & $1986-1990$ & & \\
\hline Móstoles & 58.424 & 74.000 & 24.873 & 16.885 & & \\
\hline Fuenlabrada & 11.021 & 59.748 & 41.752 & 24.875 & & \\
\hline Parla & 20.349 & 25.756 & 7.645 & 5.944 & & \\
\hline Zona Suroeste-1 & 89.794 & 159.504 & 74.270 & 47.704 & & \\
\hline \multicolumn{7}{|c|}{ Fuente: Censos y padrones. } \\
\hline \multicolumn{7}{|c|}{ INCREMENTO RELATIVO DE LA POBLACIÓN POR PERIOODOS: 1971-1990 } \\
\hline MUNICIPIOS/PERIOODO & $\begin{array}{c}1971-1975 \\
(\%)\end{array}$ & $\begin{array}{c}1976-1980 \\
(\%)\end{array}$ & $\begin{array}{c}1981-1985 \\
(\%)\end{array}$ & $\begin{array}{c}1986-1990 \\
(\%)\end{array}$ & & \\
\hline Móstoles & 327,56 & 97,04 & 16,55 & 9,64 & & \\
\hline Fuenlabrada & 150,42 & 325,64 & 53,46 & 20,76 & & \\
\hline Parla & 199,25 & 84,27 & 13,57 & 9,29 & & \\
\hline Zona Suroeste-1 & 253,83 & 127,43 & 26,09 & 13,29 & & \\
\hline Fuente: & & & & & & \\
\hline
\end{tabular}

Fig. 1. 
El crecimiento demográfico durante los años setenta se apoya fundamentalmente en los movimientos migratorios. Del cuarto de millón de personas que vienen a vivir aquí, sólo un $36 \%$ son el resultado del crecimiento vegetativo, siendo el restante $64 \%$ producto de la emigración desde el interior de Madrid o desde los núcleos de la primera corona metropolitana. Hasta la zona se trasladan numerosos matrimonios jóvenes con un nivel de renta y cualificación baja, que se desplazan buscando un piso barato que no encuentran en las zonas de las que vienen. En el año 1980 el precio medio de vivienda construida en la corona provincial, era menos de la mitad que en el núcleo interior de la capital, desde las $27.500 \mathrm{pts} / \mathrm{m}^{2}$ a las $60.000 \mathrm{pts} / \mathrm{m}^{2}$, respectivamente (COPLACO, 1981). Este aumento de la población se traduce también en un crecimiento urbano e industrial muy anárquico, que ha generado importantes desequilibrios, algunos de los cuales todavía persisten, como por ejemplo el empleo-residencia. Hay que tener en cuenta que el número de viviendas pasó de algo más de 13.200 en 1970 a 115.700 en 1980, y la superficie y el empleo industrial entre 1973 y 1980 , de 151 hectáreas y 10.000 empleos a 245 hectáreas y 16.000 empleos. Ello ha dado lugar a carencias de equipamientos, infraestructuras y servicios, incapaces de atender esta «explosión" de la demanda.

Durante los años ochenta la población crece a un ritmo más lento, en torno al $26,09 \%$ entre 1981 y 1986 , y aún más despacio en el periodo 1986-1991 (13,29\%). En este último año se llega en la Zona Suroeste-1 a los 406.648 habitantes, advirtiéndose igualmente diferencias en el crecimiento de los distintos núcleos. Es Fuenlabrada quien más crece en los dos quinquenios $(53,46 \%$ en el primero y $20,76 \%$ en el segundo). El Censo de 1991 aporta los siguientes datos de interés: casi la mitad de su población tiene menos de veinticinco años $(46,41 \%)$, sólo el $5,52 \%$ de la misma ha nacido en los municipios de la zona y casi una cuarta parte de la hoy existente vivía fuera diez años antes.

\section{LA TRANSFORMACIÓN URBANA DE FUENLABRADA Y LOS PROBLEMAS HEREDADOS}

El crecimiento urbano, experimentado en los años setenta y ochenta por Fuenlabrada, es un claro ejemplo de actuación de la iniciativa privada en un mercado de competencia por el espacio y falta de planificación urbana, al menos en sus orígenes, por parte de las entidades públicas, regionales y locales. La explicación a este crecimiento urbano hay que buscarla en el proceso de desarrollo metropolitano, que desplaza hacia la 
periferia la mayor parte de la actividad edificatoria. Un suelo abundante y barato, junto a la ausencia de planes urbanísticos y la permisividad de las corporaciones locales en la concesión de licencias de construcción, es aprovechado por las promotoras para la edificación de grandes promociones inmobiliarias.

Todo ello derivaría finalmente en una transformación masiva del suelo rural en urbano. Entre 1971 y 1980 se solicitan 364 licencias, lo que supone 56.077 viviendas (entre 1973 y 1974 se legalizaron el $84,50 \%$ de las mismas). De éstas únicamente el $4,96 \%$ estaba situado en el interior del casco urbano. El proceso se enmarca en el importante crecimiento del Área Metropolitana de Madrid, que originó la formación de "ensanches metropolitanos" a partir de municipios rurales con escasos efectivos demográficos, dando así lugar a "ciudades dormitorio" con semejantes características y problemas.

En relación a las regularidades espaciales de la función residencial, se señala que durante el período de la construcción masiva de vivienda el casco urbano de Fuenlabrada apenas ha sido transformado, conservando en parte su primitivo aspecto rural. Las principales operaciones inmobiliarias han tenido lugar a cierta distancia del centro urbano. Por otro lado la construcción de vivienda ha estado muy concentrada en el tiempo, entre los años 1975 y 1982. En estos momentos destaca el bajo nivel de estructuración territorial, una vez que las densidades de edificación aparecen marcadas claramente con la distancia. Las mayores densidades tienen lugar en el cinturón espacial que rodea el primitivo núcleo, descendiendo progresivamente a medida que nos alejamos, buscándose la mayor ventaja que genera la centralidad. Otros aspectos de interés son la homogeneidad del tipo de vivienda en cuanto a calidades y precios se refiere, la falta de una adecuada red de comunicación interior, la insuficiencia de infraestructuras básicas, el desequilibrio población-empleo y el déficit de equipamientos.

Todo el conjunto de operaciones urbanísticas al producirse muy concentradas en el tiempo y estar alejadas del centro urbano, especialmente las más grandes, dan lugar a núcleos inconexos y poco estructurados que presentan importantes desequilibrios, determinando la heterogeneidad de distritos y barrios. Ya desde mediados de los años ochenta e incluso antes se produce una ralentización del crecimiento urbano. En estos momentos son muchos los pisos que permanecen vacíos y sin posibilidades de venta, lo que a su vez trae un cierto parón en la construcción de nuevos edificios. El Plan General de Ordenación Urbana indica que alrededor de un $10 \%$ de las viviendas construidas estaban vacías a mediados de los años ochenta. 
Esta ralentización del sector se fue superando conforme se remontaba la crisis económica, aunque ya no volvería al auge anterior. En esta misma línea el Plan recoge los problemas heredados en los términos siguientes: «falta de jerarquización urbana, aislamiento físico de las promociones inmobiliarias, carencia de infraestructuras básicas, densificación de la vivienda y escasos servicios y equipamientos» (PGOU: ANEXO).

Una última e importante nota característica del crecimiento residencial de la localidad ha sido y es la existencia de una venta de vivienda de bajo precio en relación a otros espacios madrileños. Ésta se ha mantenido con altibajos en los últimos veinte años, y ha potenciado la residencia aquí de una población con un bajo nivel socioeconómico. En 1981 el precio por metro cuadrado construido en esta zona del Área Metropolitana iba desde las 25.000 o 26.000 pesetas en Parla y Fuenlabrada a las 42.000 pesetas de Getafe. En los últimos años se han disparado los precios del suelo, sobre todo en Madrid capital, pero también en la corona metropolitana (46.134 pts $/ \mathrm{m}^{2}$ construido de vivienda de nueva construcción en el año 1984 y 146.377 pts $/ \mathrm{m}^{2}$ en 1991). Los precios en Fuenlabrada sin embargo no se han elevado tanto como en los municipios de la primera corona metropolitana, que se han revalorizado con la construcción de la $\mathrm{M}-40$. De lo expuesto se deduce que el municipio seguirá concretando a nivel metropolitano una oferta de vivienda que canalice la demanda de pisos baratos, lo que de nuevo repercutirá en el asentamiento de una población con un bajo nivel socioeconómico. Sin embargo, esta afirmación vendría matizada por un cierto cambio en la oferta de vivienda, que ha variado con la introducción de los adosados unifamiliares, de gran auge en toda la región.

\section{DELIMITACIÓN DEL ESPACIO URBANO DEL MUNICIPIO}

El conjunto de barrios y distritos de Fuenlabrada pueden encuadrarse a su vez, y tal como señala el Plan General de Ordenación Urbana, en tres grandes núcleos urbanos básicos, que forman parte del término municipal y aparecen unidos mediante el nexo del eje Este-Oeste (fig. 2):

- Fuenlabrada Centro: se concentra el conjunto de actividades más urbanas, mayoritariamente residenciales y de servicios, con la inclusión de algunos polígonos industriales.

- Fuenlabrada Este: sector de actividad preferentemente industrial, a caballo de la carretera nacional 401 y su cruce con la carretera de Fuenlabrada a Pinto (eje Este-Oeste). 


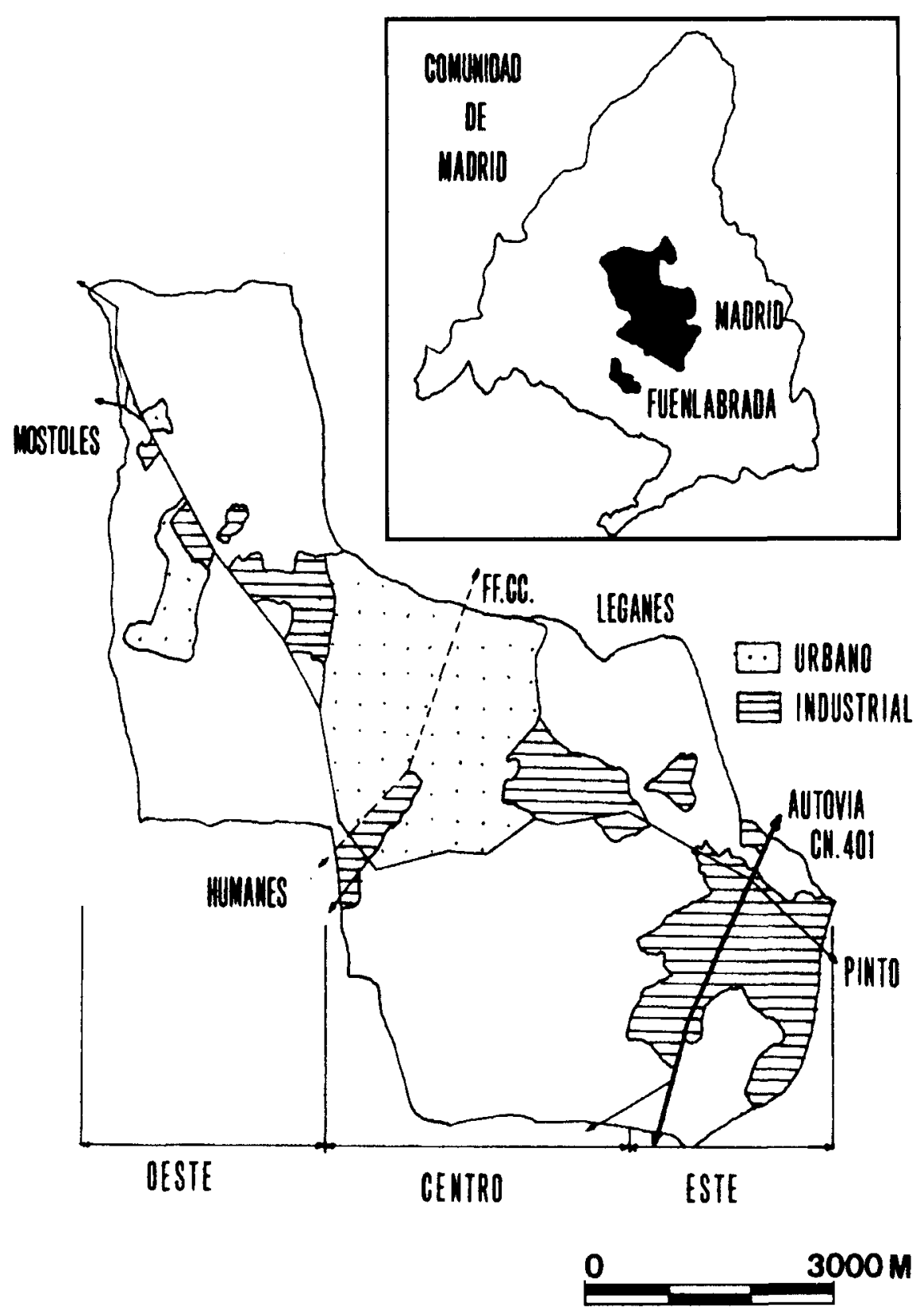

Fig. 2. Núcleos urbanos y zonas industriales de Fuenlabrada. 
- Fuenlabrada Oeste: sector mixto de actividad residencial e industrial, que tiene además una importante bolsa de suelo agrícola.

Esta división de la ciudad tiene como finalidad encauzar el crecimiento urbano-industrial, impidiendo que se repitan los procesos del período de la construcción masiva de vivienda de años pasados. Las directrices del Plan General tratan de concentrar las nuevas edificaciones dentro del perímetro urbano, procurando rellenar los espacios intersticiales. En la actualidad este objetivo parece conseguido en la medida en que los tres núcleos urbanos todavía aparecen separados con franjas de terreno agrícola, rompiendo asi con la continuidad de los asentamientos.

Vamos a centrar nuestra atención ahora en Fuenlabrada Centro y Oeste, pues en estos espacios se ubica casi toda la edificación residencial y la mayoría de los barrios de la ciudad. Son cinco los distritos: Centro, Norte, Noroeste, Oeste y Sur y 18 los barrios (fig. 3).

\subsection{Núcleo histórico y primeros ensanches}

Hasta los años sesenta Fuenlabrada tiene la morfología y estructura urbana de un pueblo rural: manzana cerrada y vivienda entre medianerias con grandes patios para usos agrícolas. El núcleo histórico en la actualidad coincide con el denominado Casco Urbano, y se localiza en el cruce de las carreteras Móstoles-Pinto y Leganés-Humanes. Se trata de un núcleo típicamente rural, que se ha beneficiado de dicha accesibilidad y de la proximidad de la línea del ferrocarril. Estructura y morfología responden a manzanas cerradas y a casas bajas de una o dos alturas entre medianerías, que dan lugar a calles estrechas y frecuentemente congestionadas por el tráfico. Las viejas edificaciones, al perder su utilidad agrícola, han sido en parte demolidas y sustituidas por otras construcciones, que han roto en buena parte del casco histórico con el espacio original. Los usos de la edificación son residenciales, aunque se suceden los comercios en las plantas bajas de las calles más transitadas del centro urbano. El eje vertebrador es el antiguo camino de Móstoles a Pinto, que de Este a Oeste cruzaba el pueblo por la mitad. Aquí se encuentran los edificios históricos, como la Iglesia y el Ayuntamiento, asi como un buen número de comercios que reflejan el carácter de paso que la calle tenía y sigue teniendo en relación a la ubicación aquí de buena parte de los servicios municipales.

Los primeros ensanches, construidos a finales de los años sesenta y primeros setenta, presentan un desarrollo a lo largo dos ejes, Este-Oeste 

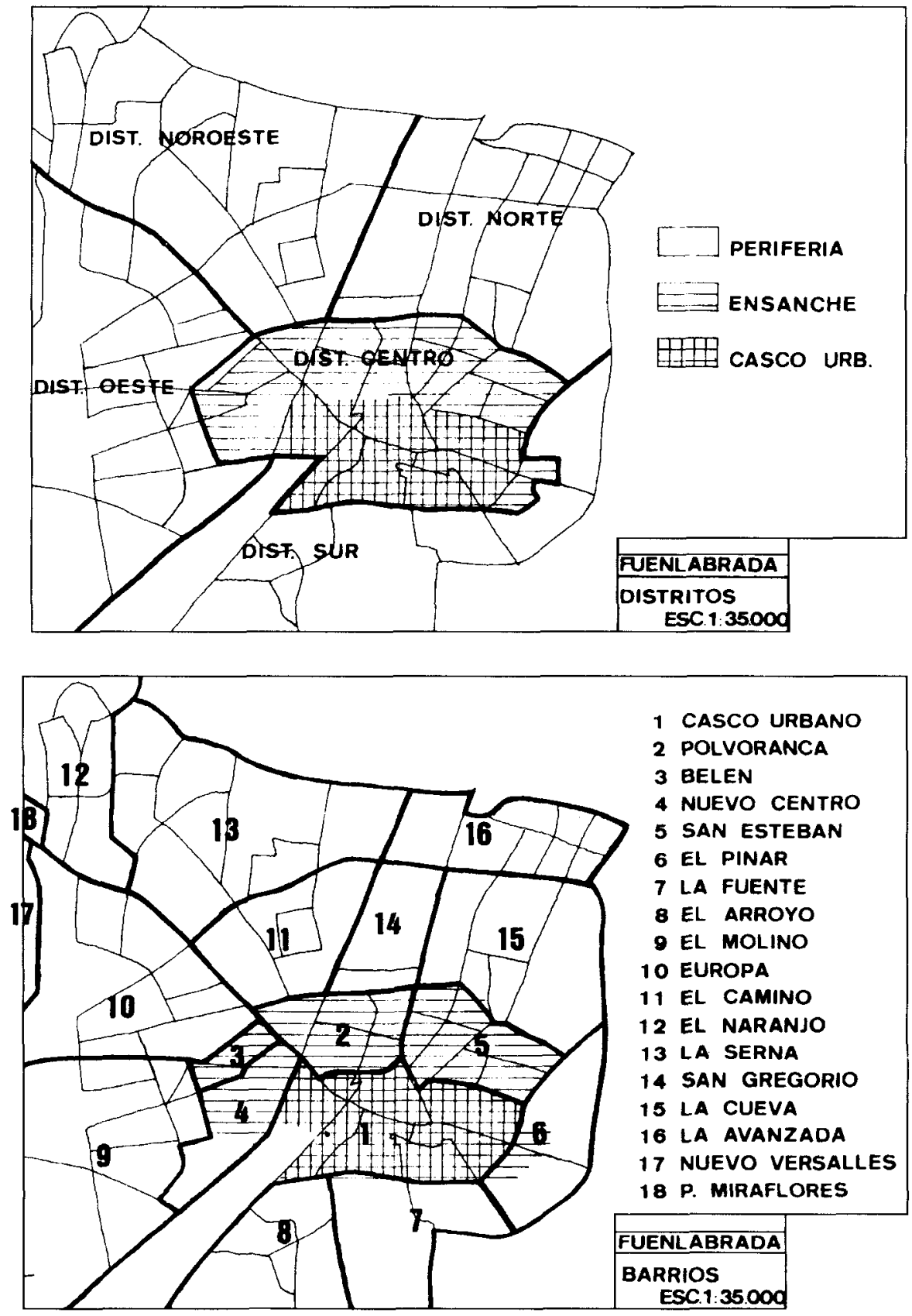

Fig. 3. 
y Norte-Sur, en un crecimiento lineal que articulará posteriores asentamientos. El primero tiende a unir la localidad de Móstoles al Oeste, con el importante núcleo industrial situado al Este del término municipal (en el cruce con la autovía de Toledo). El segundo Fuenlabrada con Madrid, crecimiento que se ve frenado por la proximidad del límite administrativo de Leganés. Las edificaciones se sitúan de forma dispersa rodeando el casco histórico, en colonias y promociones donde predomina la edificación abierta y la vivienda en bloques que no sobrepasan los cuatro pisos de altura.

1. Distrito Centro: delimitado por la primera ronda incorpora el viejo casco urbano y el primer crecimiento o ensanche. Tiene una superficie de 122 hectáreas y una población de 33.200 habitantes a finales del año 1988. Se articula en torno a dos calles, una de dirección Oeste-Este que recibe diversos nombres en cada uno de sus tramos (calle de Móstoles, de la Iglesia y de la Constitución) y otra de dirección Norte-Sur con las denominaciones de Luis Sauquillo y Leganés. La vía del ferrocarril divide el distrito en dos, dejando dos barrios al otro lado de la traza, Belén y Nuevo Centro, que se continúan en los distritos periféricos. La estación principal de ferrocarril se incluye también en el distrito y vinculándose a ésta, el que se apunta como nuevo centro de la ciudad, el Nuevo Centro CAESI. La línea del ferrocarril que atraviesa de Norte a Sur Fuenlabrada tiene un considerable efecto barrera no sólo en el distrito central, sino también en la comunicación del resto de la ciudad. Sin embargo, como contrapartida éste canaliza hoy buena parte de los desplazamientos que hacen los residentes que trabajan en Madrid. Puede señalarse finalmente que es éste el espacio más heterogéneo de Fuenlabrada.

Consta de seis barrios y 21 secciones censales:

- Casco Urbano: 9.060 habitantes.

- Polvoranca: 7.748 habitantes.

- Belén: 2.828 habitantes.

- Nuevo Centro: 1.372 habitantes.

- San Esteban: 9.629 habitantes.

- El Pinar: 2.563 habitantes.

\subsection{Distritos periféricos}

Se localizan en torno a la primera ronda de circunvalación y ocupan las tres cuartas partes de la superficie urbana de Fuenlabrada. Éstos han 
sido el resultado del crecimiento residencial de los setenta y ochenta, constituyendo hoy los ensanches más recientes. La morfología urbana responde a una edificación abierta formadas por bloques de disposición variable en unos casos y adoptando formas más regulares en otros. Es precisamente la disposición más irregular la que da lugar a un sistema de plazas y espacios abiertos poco estructurados.

La tipología edificatoria es bastante homogénea y se configura dentro de una oferta de vivienda barata, aunque dentro de la misma se advierten diferencias (calidad de los materiales empleados, aprovechamiento del espacio construido, etc.). Estas peculiaridades de la edificación traducen de alguna manera una diferenciación del espacio social. La edificación de bloques repite indefinidamente los mismos modelos: edificios de formas regulares $(H, T$ u otras), exentos o adosados por agregación simple, en hilera o en dientes de sierra. Las alturas varían entre las cuatro y nueve plantas, con cuatro viviendas por piso. Las promociones inmobiliarias se identifican muy fácilmente en la localidad por el tipo de construcción, que por otro lado destaca más por lo repetitivo que por la variedad. Con el objetivo de romper con esta uniformidad el Plan General planteaba introducir una mayor variedad tipológica, cuyo fin era el relleno de los solares y espacios libres en el interior de la ciudad y en los bordes del núcleo urbano, así como la elevación del nivel socioeconómico a partir de la incorporación de residentes con mayores niveles de renta.

La superficie de los ensanches, que actualmente constituyen los distritos periféricos del municipio, es a comienzos de 1989 de 494 hectáreas y su población de 99.996 habitantes. Veamos por separado cada uno de los distritos:

2. Distrito Norte: su superficie es de $\mathbf{1 1 5}$ hectáreas y su población de 23.173 habitantes. Sus viarios principales son la calle de Leganés que cruza el distrito de Norte a Sur y la Avenida de la Hispanidad de Oeste a Este. Sus límites son al Sur el distrito centro y al Oeste la vía del ferrocarril.

Son tres los barrios y 15 las secciones censales que lo componen:

- San Gregorio: 3.651 habitantes.

- La Cueva: 8.789 habitantes.

- La Avanzada: 10.733 habitantes.

3. Distrito Noroeste: tiene una superficie de $\mathbf{1 5 6}$ hectáreas y una población de 32.371 habitantes. Sus viarios principales son la calle de Móstoles, que la separa del Distrito Oeste, y las Avenidas de España y las Provincias. El distrito tiene también como límite al Este del mismo el ferrocarril. 
Son tres sus barrios y 16 las secciones:

- El Camino: 8.000 habitantes

- El Naranjo: 10.468 habitantes

- La Serna: 13.903 habitantes.

4. Distrito Oeste: la superficie es de 130 hectáreas y alberga una población de 35.555 habitantes. Sus principales viarios son dos grandes avenidas, la de Europa y Francia, y la calle de Móstoles que lo separa del Distrito Noroeste. Tiene como límites la vía del ferrocarril al Sur y los barrios de Belén y Nuevo Centro al Este.

Consta de dos barrios y 17 secciones censales:

- El Molino: 18.340 habitantes.

- Europa: 17.215 habitantes.

5. Distrito Sur: la superficie es de 93 hectáreas y la población de 8.897 habitantes. Es el distrito más pequeño en extensión y población, y se articula en relación a dos importantes viarios: la Calle Luis Sauquillo, salida de Fuenlabrada hacia Humanes de Madrid y conexión de la zona industrial de la Estación, y la calle de Extremadura, que la separa por el Norte del distrito Centro.

Son dos los barrios y seis las secciones censales:

- La Fuente: 1.050 habitantes.

- El Arroyo: 7.847 habitantes.

El otro gran núcleo residencial es Fuenlabrada Oeste, de reducidas dımensiones con respecto a Fuenlabrada Centro; solamente 22,6 hectáreas de superficie y una población de 3.054 habitantes. Este espacio se encuentra más cerca del núcleo de Móstoles que de Fuenlabrada. Consta de dos barrios que se corresponden con sus dos secciones correspondientes: Nuevo Versalles (1.780 habitantes) y Parque Miraflores (1.274 habitantes).

\section{PLANEAMIENTO URBANISTICO: ANÁLISIS DEL PLAN GENERAL DE ORDENACIÓN URBANA DE 1986}

El problema planteado por el crecimiento urbano de Fuenlabrada ha sido abordado por las sucesivas corporaciones locales, y en esta línea se inscriben las directrices reguladoras de usos y edificación adoptadas en el Plan General de Ordenación Urbana del año 1986. Pasamos previamente 
a señalar los antecedentes del planeamiento urbano del municipio, para luego centrarnos en el análisis del PGOU.

Hasta el año 1977, el único instrumento urbanístico utilizado para legalizar la transformación de suelo rústico en urbano fue la concesión de licencias de construcción, siendo el único requisito para edificar el ser propietario de la parcela o solar donde se iba a realizar la operación. En este año Fuenlabrada aprueba unas Normas Complementarias y Subsidiarias de Planeamiento, normativa que trata de encauzar el crecimiento anárquico de la concentración residencial-industrial que venía produciéndose por entonces. Los resultados serán muy pobres, pues la situación viene condicionada por el elevado número de licencias de construcción que ya habían sido concedidas.

\subsection{Marco de desarrollo}

El PGOU de Fuenlabrada se inicia en 1979 con los trabajos de información urbanística y diagnóstico, finalizando esta primera etapa en 1982 cuando se acabó el Avance del mismo. Se destacaba en éste la complejidad de las soluciones de ciertos problemas, recomendándose que no se procediera a la rápida redacción definitiva del Plan. Éste se encuadra dentro de las Directrices de Planeamiento Territorial Urbanístico para la Revisión de los Planes Generales de los términos municipales de Alcalá de Henares, Fuenlabrada, Móstoles y Parla (CoplaCo, 1982), que tratan de concretar los aspectos ya desarrollados en las Directrices de Planeamiento para el Área Metropolitana Institucional (COPLACO, 1980).

En este documento se insiste en los déficits de urbanización, infraestructura y equipamientos de estas localidades, y se apuesta por la necesidad de la inversión pública. Se señala que desde el Planeamiento, en los municipios de la Zona Suroeste-1 se debería atender los siguientes cinco aspectos en el marco de las directrices generales (COPLACO, 1982: 31-32):

a) Reestructurar y equilibrar la zona, dotándola por un lado de una estructura comarcal con mayor grado de autosuficiencia, contemplando al mismo tiempo, su relación con las áreas geográficas más al Sur.

b) Desaconsejar un mayor crecimiento urbano a estos municipios, orientando el desarrollo de modo que permita reequipar y completar la trama urbana existente actualmente.

c) Preservar los terrenos agrícolas de calidad, tanto de secano como de regadío, del desarrollo urbano (residencial e industrial). 
d) Potenciar la implantación industrial en polígonos ya consolidados, bien comunicados, que ayuden a completar la estructura urbana, fomentando las implantaciones de pequeñas y medianas industrias.

e) Impulsar la localización de actividad terciaria en los centros urbanos, y especialmente en las áreas en torno a las estaciones ferroviarias.

Tomando como punto de partida el Avance de 1982, y una vez contrastada la viabilidad económica y su adecuación, el Plan se formula y se redacta. Éste sería aprobado cuatro años más tarde, en febrero de 1986, tratando de encauzar los compromisos y expectativas del Ayuntamiento para acabar de estructurar Fuenlabrada, en unos momentos que como ya hemos señalado eran particularmente difíciles. El Plan comprende los siguientes documentos: memoria, anexos a la memoria (población-vivienda, estructura urbanística, políticas sectoriales y breve estudio sobre la viabilidad de un nuevo centro urbano), normas urbanísticas, programa de actuación y estudio económico financiero y planos, desarrollándose éste mediante los instrumentos de planificación, gestión y ejecución previsto en la Ley del Suelo (Programas de Actuación Urbanística, Planes Parciales, Planes Especiales, Estudios de Detalle y Ordenanzas).

\subsection{Objetivos}

EI PGOU de Fuenlabrada desarrolla en el municipio los objetivos que con carácter general señalaban las Directrices antes comentadas, y en su declaración de intenciones señala la necesidad de mejorar la situación metropolitana de la zona sur, completar la ciudad, y actuar positivamente sobre los recursos básicos del municipio.

La plasmación concreta podría verse en función de tres grandes objetivos y propuestas:

1. Inserción de Fuenlabrada en la Comarca Sur del Área Metropolitana de Madrid: se pretende potenciar la estructura interna de esta comarca, con una personalidad que viene caracterizada por la localización de los sectores sociales de rentas más bajas y el importante crecimiento urbano e industrial durante los últimos años. Se trata también de mejorar las relaciones con el Centro, mediante la inserción de la localidad en el sistema de comunicaciones y transporte metropolitano.

2. Creación de nuevos centros urbanos que articulen la nueva ciudad: se plantea por un lado la creación de un nuevo área de centralidad local en torno a la estación de ferrocarril, el llamado Centro-CAESI, donde se dispondrán los nuevos usos de centralidad de rango ciudad: actividades 
institucionales, comerciales, terciario, asistenciales y equipamientos, que aparecerían vinculadas a este importante intercambiador de transportes. $Y$ por otro, un sistema de centros urbanos de segundo orden en los distintos distritos de la ciudad, lo que permitiría dar vida a los barrios que los integran.

3. Potenciación del eje Este-Oeste: mejorar la conexión entre los tres grandes vias de penetración a Madrid (N-IV, N-401 y N-V) y las zonas industriales de Móstoles, Fuenlabrada y Pinto y Valdemoro, pretendiéndose que sea un importante eje de actividad económica y marco del empleo en la zona.

La filosofía que impregna todo el reglamento se resume en la idea de racionalizar el crecimiento de una ciudad que, a finales de los años setenta, era modelo de especulación del suelo en los municipios de la periferia madrileña.

\subsection{Coordenadas generales de actuación}

En relación a nuestra investigación destacamos aquéllas que se producen sobre suelo urbano, para lo que se concreta previamente la propuesta de clasificación-calificación de usos del suelo, que aparece detallada en el cuadro siguiente y la figura 4.

\section{CLASIFICACIÓN-CALIFICACIÓN DEL SUELO MUNICIPAL DE FUENLABRADA}

\begin{tabular}{lc}
\hline Urbano municipal-Zona Centro & $582,4 \mathrm{Ha}$. \\
Urbano residencial-Zona Oeste & $22,6 \mathrm{Ha}$. \\
Urbano industrial & $419,3 \mathrm{Ha}$. \\
\hline Total suelo urbano & $1.024,3 \mathrm{Ha}$. \\
\hline Urbanizable no programado-Zona Centro & $34,1 \mathrm{Ha}$. \\
Urbanizable no programado-Zona Oeste & $47,8 \mathrm{Ha}$. \\
Urbanizable no programado mixto & $29,0 \mathrm{Ha}$. \\
Urbanizable no programado industrial & $96,2 \mathrm{Ha}$. \\
\hline Total suelo urbanizable no programado & $207,1 \mathrm{Ha}$. \\
\hline No urbanizable deportivo & $29,1 \mathrm{Ha}$. \\
No urbanizable espacios naturales & $277,3 \mathrm{Ha}$. \\
No urbanizable agrícola & $2.372,2 \mathrm{Ha}$. \\
\hline Total suelo no urbanizable & $2.678,6 \mathrm{Ha}$. \\
\hline Total suelo municipal & $3.910,0 \mathrm{Ha}$. \\
\hline
\end{tabular}

Fuente: Plan General de Ordenación Urbana de Fuenlabrada, 1986. 


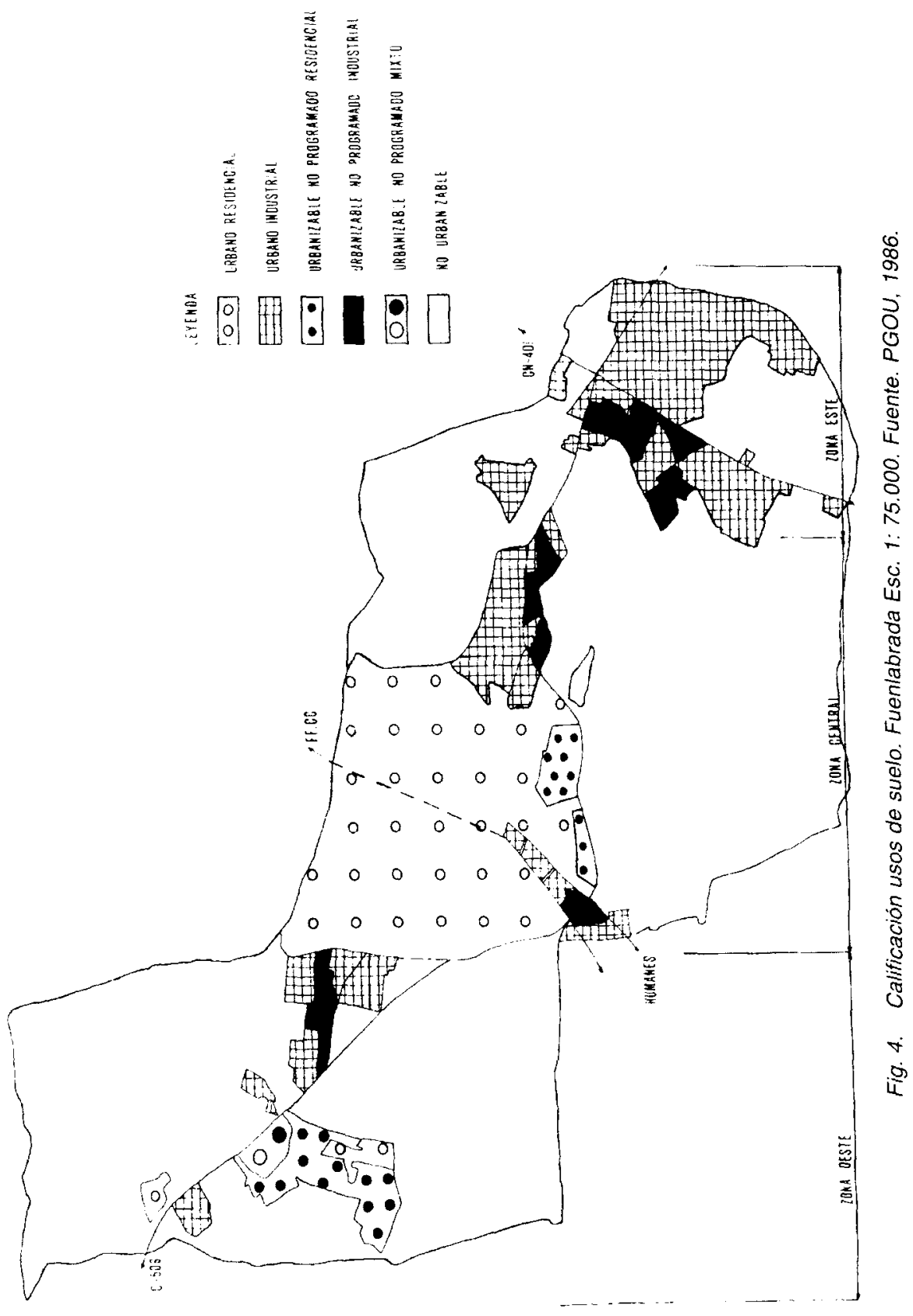


El Plan hace una regulación del suelo acorde con la nueva política urbanística del Ayuntamiento, calificándose éste en las diferentes categorías contempladas en la Ley. Se distingue un Suelo Urbano de carácter residencial, con una superficie de 582 hectáreas en Fuenlabrada Centro y 22,6 hectáreas en la Zona Oeste. Dentro de éste puede señalarse un suelo consolidado que ya no precisa planeamiento, y que vendría dado por todo lo construido hasta mediados de los años ochenta, y un suelo vacante. En este último se distinguen a su vez unas actuaciones ya comprometidas (sobre todo en los barrios de la Serna y en Europa, donde se concretan más de la mitad), y en distinto grado de consolidación y pendiente de desarrollo. Finalmente, la regulación del suelo urbano contempla también diferentes grados de consolidación: edificación colectiva entre medianerías, edificación colectiva en bloque abierto y edificación unifamiliar (grados 1,2 y 3 , respectivamente). Con respecto al Suelo Urbanizable No Programado (207,1 hectáreas en el término municipal), se contempla éste en el Sur del núcleo urbano (barrios del El Arroyo y La Fuente) y en la Zona Oeste. A su vez se concretó un suelo de uso mixto, residencial-industrial (29 hectáreas en Fuenlabrada Oeste).

\subsection{Resultados y valoración}

Con respecto al Suelo Urbano Residencial habría que destacar un conjunto de actuaciones como resultado de las directrices contempladas en el Plan. Destacamos entre las llevadas a cabo en la segunda mitad de los años ochenta y primeros noventa, el relleno de numerosos solares dentro de la trama urbana, mediante la adopción de tipologías edificatorias similares a las existentes (bloques de pisos), aunque introduciendo una menor altura y prestando mayor atención a su relación con alineaciones y linderos.

También se introducen nuevas tipologías de edificación, en espacios de tamaño suficiente como para producir una modificación de carácter morfológico, como es el caso de las viviendas unifamiliares, auténtica novedad en estos últimos años. Son numerosos los edificios que se están construyendo a finales de los años ochenta y principios de los noventa, obedeciendo muchos de éstos a nuevas tipologías de edificación. El Plan General planteaba como principal problema de la vivienda de cara al futuro, la necesidad de conectar en cada momento con la demanda metropolitana. $Y$ es precisamente la diversificación de la demanda la que ha permitido variar al menos una parte de la oferta local. Son las viviendas unifamiliares, y dentro de éstas las colonias de adosados, los grandes protagonistas de buena parte de los núcleos metropolitanos madrileños y del crecimiento de 
Fuenlabrada a comienzos de los años noventa. Esta novedad constructiva rompe en la ciudad con la monotonía de los bloques abiertos y puede ser determinante en la elevación del nivel socioeconómico de la zona en la que se asientan.

Resumiendo, el conjunto de las nuevas edificaciones construidas recientemente obedece a dos claras tipologías: bloque de varias alturas en manzana abierta y vivienda unifamiliar. Éstas se encuentran repartidas de forma irregular, aunque se localizan sobre todo en los barrios situados al Norte de la ciudad (La Serna, Europa y La Cueva). Otras actuaciones son más concretas, como en el Casco Urbano, donde estas viviendas vienen a rellenar solares. Son también significativos los nuevos bloques de pisos, que sin romper con la tipología edificatoria anterior introducen una mayor calidad en la misma (Europa y La Serna). Otros bloques en otros barrios repiten los tipos de construcción de los últimos veinte años.

A su vez se ha potenciado la urbanización del municipio, haciéndose una clara definición de la trama viaria y de los espacios públicos. Se han creado nuevos equipamientos y zonas verdes que han permitido una mayor habitabilidad social del espacio urbano; parques hoy ocupan los espacios libres que habían quedado entre las diferentes promociones inmobiliarias. Todo ello ha posibilitado canalizar de una forma más racional el crecimiento urbano y demográfico actual, que aunque a unos ritmos más lentos que en la etapa precedente hoy sigue produciéndose.

Por lo que respecta al Suelo Urbanizable No Programado, habría que señalar que éste se dimensionó en exceso, pues en su momento se estableció en función de unas expectativas de crecimiento demográfico y de vivienda que se tenian por entonces y que no se han cumplido. Buena muestra es la población que se estimó por entonces, cifrada en 196.963 habitantes para el año 1993, cuando sólo se ha llegado a 155.168, unos 40.000 menos. El suelo previsto en barrios como El Arroyo y La Fuente no se ha ocupado, y con respecto a Fuenlabrada Oeste, el otro gran espacio en el que se preveia este tipo de suelo, no ha tenido ningún tipo de crecimiento por lo problemático de las actuaciones pasadas (en el contexto de un conocido "affaire inmobiliario"). En 1993 y después del derribo de las edificaciones no terminadas de Nuevo Versalles, se está potenciando desde instancias regionales y locales una gran actuación urbanística, que de llevarse a cabo podría repercutir positivamente en la zona. Sobre este espacio se contempla la creación de Loranca Ciudad-Jardín, barrio residencial que según proyecto supondrá 7.000 nuevas viviendas unifamiliares y colectivas. Se ha constituido al efecto un consorcio integrado por el Instituto de la Vivienda de Madrid (IVIMA) y por el Ayuntamiento de Fuenlabrada. 
Haciendo una valoración de los objetivos del Plan en función de lo conseguido, habria que poner en el haber la mejora del espacio urbano y la creación de nuevos centros, conjunto de actuaciones que han favorecido la habitabilidad de la localidad y han ayudado en definitiva a "crear ciudad". $Y$ en él debe la terminación de lo programado en el nuevo Centro-CAESI y la creación de empleo; esto último en relación al desarrollo de actividades terciarias de ámbito local, no consiguiéndose romper con el desequilibrio población-empleo que viene teniendo desde hace años. Desde 1992 y coincidiendo con la crisis, se produce también una importante pérdida de empleo en el sector de naves industriales de Fuenlabrada.

\section{CONCLUSIÓN}

En la actualidad nos encontramos ante una dinámica de crecimiento urbano diferente al de los años pasados. Ello puede tener a medio plazo una clara implicación en la elevación del nivel socioeconómico del municipio al asentar a una población con mayores niveles de renta. Las nuevas construcciones atienden las necesidades de alojamiento y al mismo tiempo revalorizan el conjunto de la ciudad, diversificando y enriqueciendo la uniforme oferta inmobiliaria realizada con anterioridad, tratando de cubrir igualmente las nuevas demandas de vivienda. El gran reto para el futuro es solucionar las necesidades de alojamiento de una población joven en crecimiento, para que no tenga que emigrar como sus padres, ayudando asi a la integración social y espacial de sus ciudadanos.

En resumen, la mejora del espacio urbano sí es hoy una palpable realidad, y sobre todo si lo comparamos con la situación a finales de los años setenta. Ello ha favorecido una mejora en la habitabilidad de los barrios de la ciudad, cubriendo así uno de los objetivos propuestos por el Plan General de Ordenación Urbana. 


\section{BIBLIOGRAFIA}

Ayuntamiento de Fuenlabrada: Plan General de Ordenación Urbana. 1986.

COPLACO: Directrices de planeamiento territorial urbanístico par la revisión de los planes generales de los términos municipales de Alcalá de Henares, Fuenlabrada, Móstoles y Parla. Madrid, 1982.

COPLACO: Informe sobre ordenación del territorio en el área metropolitana de Madrid. Bases para un debate. MOPU. Madrid, 1980.

COPLACO: Informe sobre modificación de las normas complementarias y subsidiarias de Fuenlabrada. MOPU. Madrid, 1976.

Díaz ORuetA, F.: «Ralentización del crecimiento y desconcentración demográfica en la Comunidad de Madrid". Alfoz, no 71, pp. 41-45, 1990.

Diputación Provincial de Madrid: Cooperación provincial a los municipios. Edita Comercial Consa. Madrid, 1956

Estébanez, J. (Editor): Madrid, presente y futuro. Akal. Madrid, 1990.

Fernandez Magán, $C$.: «Migraciones centro-periferia en la Comunidad de Madrid: un análisis". Alfoz, no 65, pp. 65-70, 1989.

Garcí, C.: «La población de la Comunidad de Madrid en 1986». Alfoz, no 71, pp. 65-71, 1990.

Madoz, P.: Madrid, Audiencia, Provincia, Intendencia, Partido y Villa. 1848.

MÉNDEZ, R.: «Crecimiento periférico y reestructuración metropolitana: EI ejemplo de Madrid». Alfoz, no 71, pp. 47-53, 1990.

Santos Preciado, J. M.: El modelo de diferenciación residencial del sector Suroeste del Área Metropolitana de Madrid. Edita Universidad Complutense, 2 vol. Madrid, 1988.

ToBio, C.: «Procesos de reestructuración territorial en el Área Metropolitana de Madrid». Alfoz, nº 21/22, pp. 49-66 y nº 23, 1985. 